\title{
Culture, Government and Development in South Korea
}

\author{
Luis Felipe Ramírez \\ School of Humanities and Social Sciences, Tecnológico de Monterrey, Mexico City Campus \\ Calle del Puente 222, Col. Ejidos de Huipulco, Tlalpan, 14380, México, D.F., Mexico \\ Tel: 52-55-5483-2020 x 2321 E-mail: luramire@itesm.mx \\ Julio E. Rubio (Corresponding author) \\ Direction of Research and Graduate Studies, Tecnológico de Monterrey, \\ Rectoría de la Zona Metropolitana de la Ciudad de México \\ Calle del Puente 222, Col. Ejidos de Huipulco, Tlalpan, 14380, México, D.F., Mexico \\ Tel: 52-55-5483-2020 x 2399 E-mail: jerb@itesm.mx
}

This research is funded by Tecnológico de Monterrey's Research Group in Technological Innovation and Research Group in Science and Culture.

\begin{abstract}
One problem that various thinkers have studied is the relationship between culture and social development. This article will try to identify the principal characteristics of South Korean culture and its Confucian heritage as positive factors in the development of South Korea. To do so, it addresses the existence of values of Confucian origin in government and society. Next, the article reviews historical factors that played an important part in South Korean development. Finally, the authors reach the conclusion that development is possible in distinct cultural contexts, and that it is not possible to establish a deterministic connection between a specific social framework and the conditions of social development.
\end{abstract}

Keywords: Confucian cultural heritage, Development, South Korean cultural heritage

\section{Introduction}

According to Chau (1996), it is possible to understand Confucianism as an influential intellectual discourse in countries such as China, Japan, Vietnam, South Korea, Taiwan, Singapore, Hong Kong and North Korea. Confucianism has shaped the culture and traditions of this region for thousands of years. On the other hand, beginning with Japan in 1945 and South Korea, Taiwan, Singapore and Hong Kong in 1960, Eastern Asia has experienced high rates of economic growth in recent years, reason for which the region has come to be considered one of the most dynamic in the world (World Bank, 1993). This leads us to the following question: what are the reasons for the economic success of this region? We must take into account that the aforementioned nations have very different populations, cultures, geographies, etc. However, they all share Confucianism as part of their cultural heritage. For this reason, we could argue that there is a relationship between the economic success of Eastern Asia and its Confucian cultural heritage. In order to explore this question, we will review some values of Confucian influence in both South Korean governance and society, in order to establish later on how these concepts were reinterpreted and adopted just as South Korea began to deal with the pressures of development. In this way, we evaluate the idea that culture has played an important role in South Korea's development.

Various thinkers have engaged the problem of the relationship between culture and social development. The matter was first addressed by Max Weber, as a means to explain the boom in the Western civilization and especially in Protestant countries. Joseph Needham also posed the question in relation to the technological development of China. Currently, this issue arises when thinkers try to understand, for example, the rapid advance of Eastern Asian societies or the difficulties faced by Latin America. In this article, we will analyze the relationship between the Confucian cultural heritage of South Korean values and the rapid development of South Korea. In particular, we will try to identify a series of cultural elements that demonstrate coherence between the culture of public administration in South Korean and the country's social behaviors. Additionally, we will consider historical circumstances as possible factors in South Korea's 
economic and technological development. From this analysis, we will try to come to some conclusions about the structural relationships between a society's culture and its development.

It is important to clarify that we will not properly discuss the notion of development, which is problematic in itself; South Korea's economic growth in recent decades is strong enough to take it as evidence of development, at least for the purpose of this work. Regardless, for purposes of our analysis, we will reference the following characteristics of the transformation of South Korean society in the last half century: implementation of an economic model based on free trade; development of an economic structure based on business networks (chaebols) and accelerated creation of technological capacities.

We must also establish that, in this article, we do not address Confucianism in terms of the doctrine developed by Confucius. Rather, we intend to isolate some contemporary South Korean values that can be identified with South Korea's Confucian heritage. Hence, we call these values "Confucian" given previous academic associations with this school of thought. However, we do not try to prove a connection between these values and historical Confucianism. The relevance to this work is that the aforementioned values describe peculiarities of South Korean society and in this sense help us to try to understand the relationship between culture and development. As such, we speak of a culture influenced by Confucianism, rather than Confucianism proper.

\section{Confucianism, Protestantism, and Development}

Creel (1964) points out the existence of two great schools of thought in public administration, which we will call the universal and the historical-cultural schools, both of which could be used as windows into understanding Confucian cultural influence. The universal school affirms that social and cultural context are irrelevant to understanding the principles of administration as a discipline and their application. The historical-cultural school, on the other hand, upholds that administration as a discipline reflects the culture and traditions of a region. For the purposes of our investigation, we are interested in the latter school. Adopting this perspective, we have developed three lines of approach for analyzing the problem at hand: analysis of the different points of view on the relationship between values of Confucian influence and development; outlining of a basic model for public administration based on these values; and explanation of the expression of these values in the South Korean government.

We can group the theories concerning the relationship between Confucianism and development into three branches. The first branch places Confucianism as an obstacle to development, the second understands Confucianism as neutral in terms of development, and the last positions Confucianism as a catalyst for development.

Moulder (1977) points to Weber as the first to consider Confucianism as a hindrance to development. In his comparative analysis of Protestantism and Confucianism, Weber (1989) poses an important question: why did capitalism, understood as the individualistic impulse to compete and maximize profit, develop in the West but not in other places? According to Weber, the answer is that the Protestant ethic of the West set the conditions for the development of capitalism. Protestant principles make individualism, work and the pursuit of wealth a moral standard and a religious duty for all individuals.

In contrast with that of Protestantism, the principal concern of Confucianism is to offer a guide for the moral betterment of the members of a community, in order to achieve a morally harmonic society. To accomplish this goal, a Confucian society becomes hierarchical and bureaucratic, with a much stronger government than civil society. Under these conditions, the orientation towards the community has the effect of weakening individualism and, along with it, private property; as such, Confucianism prefers social normativity based on virtue to legal normativity. Weber concludes that capitalism could not emerge under these conditions. The recent economic success of countries of Confucian heritage has called into question Weber's position. Given this occurrence, some scholars argue that culture is perhaps a neutral element in the development of a country, basing their hypotheses on the supposition that if Confucianism were a positive factor in development, Eastern Asian countries would have developed a long time ago; and that, on the other hand, if Confucianism were a negative factor in development, Eastern Asian nations would not have achieved the levels of economic success that they enjoy today.

To some theorists (Hughes, 1993; Harris, 1986), development is a universal process. On some level, they appear to be correct, since development has occurred in places with different cultures, historical situations and traditions. This also demonstrates that there is no one developmental strategy that can be applied in all historical cases. The development of countries of Confucian heritage leads some theorists to conclude that these countries have put forth a new alternative to development that is opposed to the Western model and could be the mode of the future (Kahn, 1979).

It is worth mentioning that the birth of capitalism and its propagation are two related but distinct processes, and as such the role of culture can be different in these two processes. South Korea has lived a process of assimilation of capitalism, not birth of capitalism, as occurred in the West. Moreover, this assimilation has been explicit and goal oriented. It has been, then, a learning process, as Vogel (1991) indicates. In this process of assimilation, we can consider Confucianism as a positive factor, given that it promotes hierarchy, harmony and a community-oriented society, which can be 
favorable to the adoption of conditions that were originally foreign to a society. Thus, Confucianism could be considered a cultural factor that would have facilitated the arrival of Western capitalism in South Korea and been converted into a vehicle for economic development.

In our analysis, we will approach this problem through the lens of public administration. The question that we propose is whether or not Confucianism is in itself a cultural framework for understanding public administration, and if so how it has influenced the development of public administration in South Korea. In order to answer these questions, we will first review some concepts of government that can be derived from Confucianism.

\section{The Confucian Art of Governance}

According to Hsu (1975), Confucius proposes six arts of governance: rectification, Chung Yung or the Doctrine of the Mean, rule by virtue, public instruction, fostering national wealth and the consideration of public opinion. In Confucian doctrine, rectification is the clear and express establishment of the moral guidelines of a society. In other words, rectification consists of the social norms that determine right and wrong, namely the standard. This standard serves to guide the reasoning and judgments used in order to achieve collective goals and as a means of social control (Hsu, 1975). Confucius believed that governance necessitates rectification because government is the institution responsible for establishing the standards that guide actions intended to benefit a nation. Thus, when government performs its function correctly, it wins the support of the people. As such, rectification requires that every person act in accordance with his or her function and position within the government, so as to establish responsibility. This idea also allows for the establishment of standards of procedure in each sphere, since going beyond the limits of one's functions would be considered usurping. Clearly, this principle contributes to the maintenance of hierarchy and social order.

Chung Yung, or the Doctrine of the Mean, stems from the claim that society is composed of different individuals and groups with different preferences and perceptions. In order to achieve the social harmony that Confucian doctrine entails, it is essential to maintain equilibrium between these groups and individuals. This equilibrium is never static, which is why government involvement is necessary. According to Hsu (1975), practicing the Doctrine of the Mean involves the following principles: first, the masses must be governed according to their nature and all that it entails; second, the governor and the governed must have mutual trust and sympathy; third, the government must maintain consistency between words and actions; fourth, the governor must act appropriately and in accordance with the situation at hand; fifth, the government must have an appropriate knowledge of and respect for religious duties and filial piety; and last, love is the foundation of civilization and all people fall under its power.

According to Confucius, the behavior of the nation depends on the intellectual capacities of the people. The most effective way to develop the mind is moral discipline, which at the same time appeals to the goodness in human nature and leads to crime prevention. Moral discipline allows for the people to exercise self control by virtue. On the other hand, a rule by law implies prevention via sanction. From the Confucian point of view, this latter type of rule is essentially reactionary, and it only confronts the symptoms and the not core of the problem. Also, rule by law implies a coercive method of enforcement of government policies, whereas rule by virtue implies achieving a spiritual and ideological understanding with the people and thus earning the people's loyalty. Confucius believed that government by virtue would function because people are essentially benevolent; as such, the people would choose virtuous governments and reject immoral governments.

On the other hand, the instruction of the people, understood as education, is the result of the rule of virtue. A rule by virtue must consider the education of the people as its main activity. Confucianism also understands education as a moral discipline.

On the matter of wealth, Confucianism contends that government must simultaneously regulate and promote economic development. As a regulator, government must create conditions that improve the economic situation of the nation. Government must control the nation's economic resources (natural resources and endogenous materials) in order to distribute them in an equitable manner among the people. Equality and just distribution of national wealth are key elements in the socioeconomic policy of a Confucian society. What is more, the idea of a just and egalitarian distribution of wealth leads to the regulation of competition, or in terms of contemporary economics, the intervention of the government in the market. As a promoter of economic development, the role of a Confucian government is to construct and maintain infrastructure (road, bridges, telecommunications, water works, etc.) and organize the production of various capital goods. In other words, the government is responsible for instructing the people in how to produce new goods.

The last art of governance proposes the principle of considering public opinion. Confucius believed that public opinion is a manifestation of the wishes of the people. In this sense, public opinion provides feedback to the government and allows for the creation, implementation or betterment of public policy and its realization.

In all, Confucianism gives birth to a cultural framework for public administration. A Confucian government is a benevolent, united and paternalistic authority that concentrates power in a hierarchy headed by the emperor, and 
emphasizes the role of ethics as an element in good public administration, for which reason it holds the emperor and his ministers to high moral standards.

\section{The Structure of the Confucian Government}

According to Confucian philosophy, the universe is governed by the "Will of Heaven." In a more concrete sense, we can understand the Will of Heaven as the natural laws that are present everywhere. The Universe is, then, ordered, united, harmonious and continuous (Schwarzmantel, 1987). The government is a subordinate entity in the universe and must follow the order of the natural laws. In other words, a government must appear by the Will of Heaven, and only so can a government be legitimate, given that the Will of Heaven is the ultimate law of the Universe. This is the principle basis of public administration in Confucianism, and it determines the way in which the government must be structured and operate (D. Y. Lee, 1985).

If we correctly discern the Confucian concept of a government by the Will of Heaven, the structure and order of the government must be incorporated into the structure of the Universe. In this sense, the Universe is a hierarchical and unified system that concentrates all of its "power" in Heaven. Under this model, with all political power and action centered in a bureaucracy headed by the emperor, the political order is markedly monolithic. According to Confucius, the most important factor in the consolidation of the State is political unity, for two reasons: first, in order to protect the State from possible external threats; and second, in order to govern in an efficient and effective manner. In addition, Confucianism considers the State consolidated when the State achieves centralization of political authority, understood as the "power of the State" (Hsu, 1975). As a clear example in countries such as China and South Korea, we find that a central office of the government oversees the creation of all government offices that deal with national problems. As Hague, Harrop and Breslin (1992) point out, the Confucian idea of government does not accept the separation of powers as a means to balance of power, which is the essential feature of Western capitalist governments. Following Hague (et al., 1992) we can define the structure of a Confucian government as a hierarchy where functionaries are subordinated to a higher authority. Compared with idea of government held by Lincoln, who declared "government of the people, by the people and for the people," the Confucian notion supports a government of the people and for the people, but not by the people. Even though Confucian government requires the approval of the governed, this does not mean that the people can participate in the government. Confucian government is not democratic.

At this point, it is worth mentioning some similarities and differences between the Confucian and Weberian models of bureaucracy. Both models are hierarchical and require a structured system of compensation for the officials. On the other hand, in the Confucian model, division of labor, established rules and inexplicit norms of conduct are not as clear as in the Weberian model. According to Creel (1964), the most important difference between these two models is that the Confucian model is dominated by a relationship system. As a result, many of the relationships in a Confucian bureaucracy emulate familial relationships. Thus, the government is not regulated by an impersonal authority, but rather by paternalistic leaders, in this case, Mandarins. For this reason, Creel (1964) characterizes the Mandarins as the "mothers" and "fathers" of the people. In this dynamic that emulates family relationships also deforms somewhat the meritocratic principle, which is also an essential aspect of Confucian bureaucracy. Once a Mandarin enters into the government, his promotion no longer depends only of his merits and capacities, but on the health of his relationships within his work group and especially on his relationship with his superior. This inevitably makes Confucian bureaucracy paternalistic.

In terms of the cosmic order that Confucianism purports, the emperor is the worldly equivalent of this order, as the emperor is chosen by the Will of Heaven. As such, given the Confucian analogy of the family, the emperor adopts the role of husband, father and head of the family-society. As chosen by the Will of Heaven and the Universe, the emperor is prepared and authorized to make the decisions and rules of the country, for the good of the people.

In societies or countries with Confucian heritage, the majority of modern governmental institutions are copies of Western institutions, but in reality these institutions function differently than in their societies of origin. Today the governments of societies with Confucian heritage, as in the Western governments, practice the separation of the executive, legislative and judicial powers, yet it must be stressed that the relationships between these powers is very different from the way it is in the West. As we stated before, Confucianism emphasizes unity in the government, which concentrates administrative and political power in the bureaucracy. This means that Confucian countries have a higher level of political unity than Western countries. As a result, while governments in Confucian countries are unified and the executive power is more powerful than the other two powers, in the West there is a tendency towards balance between the powers (Hague et al., 1992). 


\section{Education, Meritocracy and the Effectiveness of Government}

The ideal Confucian government, as we have mentioned, is a rule by virtue. The quality of the people in the government determines the quality of this type of government, with the emperor as a model for the nation and as such whom the people will decide to imitate (Hsu, 1975). As such, the emperor's conduct must be ideal. The emperor becomes a key factor in a good government, as do his personal qualities and capacities. Given the former, the emperor must exhibit certain characteristics, such as love of the people, for only then can he be a legitimate emperor; he must be mindful that being an emperor is not a privilege, but rather a responsibility; he must also be aware that being bestowed with this responsibility is only the beginning of the learning process that will give him the status of a "wise" politician. Moreover, the emperor must be a wise man who learns quickly, sure in making decisions, in possession of extensive knowledge and intelligence and determined to govern the people. In the same way, the Mandarins that make up the government must learn quickly and be willing to do so. They must be humble and willing to ask for advice, even from those of a lower rank; they must be respectful and just. In this way, the emperor and the Mandarins develop their personal qualities in the governance process, and this process is at the same time their means of learning. This is why Confucianism places such a special emphasis on education (Hsu, 1975).

It is no surprise that Confucianism would pay special attention to the job of finding people capable of being useful to the State in the process of governance (Creel, 1964). The selection process of the designated Mandarins, or all of the functionaries below the emperor, is open to all of the public, without regards to social class. The advantage of this method is that it allows the government to select the most talented or trained individuals to work as functionaries. It also allows for the governing elite (the Mandarins) to be representative of the different social strata. As a result, the government is much closer to the people than if it were not so representative. Last, this process facilitates the conversion of Confucianism into a species of national ideology used by the government to guide and justify the manner of acting and thinking of its members. In this sense, the government reinforces its monolithic position (Creel, 1964).

Thus, in countries of Confucian heritage, the tradition of studying to become a public servant is very strong. Public service is a prestigious profession, and many well-educated and talented young people wish to become public servants. Currently, many public servants in South Korea (Kim, 1997) are graduates of the most prestigious universities (Hague et al., 1992). While public servants were once selected on the basis of their knowledge of Confucian philosophy, now public servants are selected according to their profiles, abilities and relevant technical knowledge. The selection process for public servants is, in general, meticulous, and those chosen are normally considered to be technocrats of the highest level (World Bank, 1993). On the other hand, the tradition of recruiting public servants by means of arduous testing of knowledge has meant that those chosen come from different social classes and, as such, represent the varied interests of the people.

Confucian countries pay special attention to the problem of choosing, training and developing their public servants. Let us return to the analogy between the family order and the Confucian public administration. In this analogy, superiors are responsible for their subordinate's futures (Amsden, 1989). High ranking public servants consider training, developing and searching for subordinates to be their duty. Obviously, a highly trained bureaucracy is a fundamental instrument in development. Once fitted with the most talented people in the relevant fields, the bureaucracy has relative liberty in terms of political pressure and can then formulate and implement policies aimed at the consistent and long-term development of the nation (Johnson, 1995). This evidently helps a nation to overcome a lack of capital and technology, which has be a common obstacle in many countries (Kim, 1997).

\section{Economic Development and Confucianism}

The neoclassical theory of economic development emphasizes the role of the market, while the communist theory emphasizes the role of the State (Friedman \& Friedman, 1980). Eastern Asian countries appear to suggest a third model of economic development, which combines the two theories mentioned above. Wade (1990) has called this model the "governed market," which, simply put, is a market economy with government intervention. In this model, the market is not as free as it is in the neoclassical model, yet government control is not as complete as in the communist model. The governed market model is a rational planning of the economy guided by the State.

This model allows for Confucian countries to utilize the advantages of both the neoclassical and socialist theories, and as such to diminish the failings of each system. Consequently, it is logical to ask why the governed market model has appeared in Eastern Asia. We could respond that Confucianism has been an important factor in its appearance, given that Confucianism allows for the intervention of the government in the market. When countries with Confucian heritage adopted the neoclassical model of economic development, they modified it in accordance with the Confucian spirit, as they did with the adoption of Western political institutions. Thus, we could define the governed market model of economic development as a hybrid between Confucius's idea of the role of government in economic development and the neoclassical theory. This could explain why the economy in Confucian countries behaves differently from that of other countries. The conduct of government in Confucian countries appears to be somewhere between that of capitalist and communist governments (K. Lee, 1993). The previously mentioned Doctrine of the Mean, taken from Confucius's 
vision, might be an additional factor, given that it requires that governments shy away from extremist positions in favor of a middle course.

From 1965 to 1989, Eastern Asian countries experienced a high degree of growth in GDP per capita, with low income inequality. This appears to contrast with the large inequality in income distribution that historically accompanies such growth proportions and increases in PIB per capita (World Bank, 1993). We should keep in mind that in the Confucian tradition, a legitimate government is one that can improve the quality of life of the people. In order to respond to this challenge to their legitimacy, governments in Confucian societies have chosen strategies that emphasize economic development and the principle of "shared growth." Leaders hope that the distribution of benefits and economic improvements reach the population quickly, so as to legitimate their leadership.

In Eastern Asian countries, economic development is always the first political objective and government is highly committed to achieving it. The economic achievements are distributed to the people and all benefit; these governments have had major success in the unified mobilization of the people towards economic progress. Once more, in keeping with Confucian guidelines, Eastern Asian governments reflect the notion of rectification, which implies that the policies and actions of the government be clear in the eyes of the people.

In such societies, those who are guided by the Confucian spirit do not demand democracy, but rather egalitarian treatment (Johnson, 1995). At the same time, according to Confucius, government must enrich the people. This morality has served to provide a social environment favorable to leadership and the guidance by way of an authoritarian administration style that emphasizes economic development but not democracy. The authoritarian style of the public administration has generated conditions favorable to development. The experience of many developing countries has shown that lack of political unity is often one of the principle causes of failure to achieve significant progress (Park, 1970).

If the people in the government were not highly qualified, then perhaps this authoritarian style of government would not be a positive factor in development. Confucian countries overcome this problem with the previously mentioned system for selecting public officials. The community expects public servants to behave ethically, in accordance with the principles of rule by virtue. Lodge and Vogel (1987) have pointed out that public servants in Confucian countries tend to exhibit high moral standards.

Public education is another of the Confucian arts of governance. Traditionally, the Confucian government pays special attention to education. In the past, the basis of education was learning Confucian principles. Today, governments in countries of Confucian heritage continue to cultivate learning, but with a focus on science, technology, administration (public and private) and business, fundamental to economic development (Kim, 1997). In Eastern Asia, the average enrollment at the primary and secondary levels has far surpassed expectations in relation with the income level of the population (World Bank, 1993).

Confucian countries have been successful in developing their human capital. Education policy in these countries appears to function better than in other developing countries, because government has taken responsibility for education. This has enabled governments to respond effectively in order to correct failings in the area of education (World Bank, 1993). One of the reasons for this success is that governments have managed the shift from preindustrial societies, with untrained workers and lack of technical knowledge, towards efficient and effective societies, in terms of production. Kahn (1979) points to the traditional Confucian appreciation of education as an advantage in the transformation from a preindustrial to a postindustrial society, and from there to the so-called knowledge economy.

The South Korean government used investment in education as its first step in achieving modernization, as shown by the large and sustained investment by the government in education since 1951 (Kim, 1997). The share of the total national budget dedicated to education grew from $2.5 \%$ in 1951 to $17 \%$ by 1966 (Porter, 1980). Despite this fact, the investment by the government counted for just a third of national spending on education. The rest of the investment came from the private sector and parents, which reflects the strong commitment to education by Korean society (Kim, 1997).

According to Kim (1997), given high social mobility, in South Korea advancement depends more on knowledge than social concessions. As a result, education provided results quicker in Korean development than in the development of Western countries. Since 1953 enrollment in South Korea has increased rapidly and steadily at all educational levels. By 1970 , enrollment in elementary education had grown to more than $100 \%$ from less than $60 \%$ two decades earlier. When analyzing the gains in middle and high school enrollment, we must consider that parents cover the costs of studying these levels. Nevertheless, between 1953 and 1994, enrollment in middle school increased five-fold, from $21 \%$ to $99 \%$, and secondary and tertiary enrollment had even stronger gains. During this period, the rate of high school enrollment grew from $12 \%$ to almost $89 \%$, and tertiary enrollment climbed from $3.1 \%$ to $48.8 \%$ (Table 1 ).

This effort to improve the level of education in South Korean society was not an innovative approach to development. Many other nations, such as Argentina, Brazil and Mexico, had used investment in education of a developmental 
strategy. However, the expansion of the South Korean educational system was unique because of the rapid and sustained growth at all educational levels, which was strong enough to support sustained economic and industrial development (Katz, 2000).

It is important to mention that high school education in South Korea is often vocational or "on-site." Large private firms first implemented this type of program as an incentive for their young workers and a way to retain talent. The scheme benefits both employers and employees, as it leads to increased worker productivity and generates positive attitudes in workers, since they view their jobs in terms of education and not merely work hours.

Professional education played an important part in the formation of the work force in South Korea, despite its deficiencies (Amsden, 1989). One could argue that systematic planning of human development at the professional level began with the establishment of the Professional Formation Law in 1966. In 1974, the Korean government passed a law establishing mandatory "in-plant training" for all the industrial organizations with more than 300 workers. With this law, several firms decided to establish their own institutes for professional formation in order to educate the at least $10 \%$ of their personnel each year necessary to avoid paying punitive taxes. According to Kim (1997), this law led to important increases in vocational training, which more than tripled from 31,621 in 1970 to 104,504 in 1980 (p. 61).

\section{Confucianism and Cultural Values}

South Korea's Confucian heritage is still evident. According to Kim (1997), today, Confucian teachings are much more prevalent in South Korea than they are in China, their country of origin. Still, it is worth mentioning that the arrival of Christianity to Korea in 1884 significantly modified traditional Confucian values, introducing, among other things, modern education, the vision of Western society and Protestant values. Tu Wei-ming (1984) affirms that the Western Christian ethic merged with and considerably modified the traditional Confucian ethic, in order to form a new Confucian ethic. This new Confucian ethic is an amalgam of the collectively-oriented values of the East and the goal-oriented economic values of the West. This blending of cultures profoundly altered the traditional Confucian notion of occupational hierarchy, which places intellectuals and public servants at the peak of the bureaucracy, farmers second, artisans third and merchants last; it created the possibility for modern business people and engineers to prosper in the new industrial society. Kim (1997) considers that this new Confucian ethic has some essential characteristics, which we will now describe.

Currently, South Korea places a special emphasis on education, which has led South Korean parents and their counterparts in other Eastern Asian countries that have also experienced industrialization to make enormous sacrifices in order to educate their children. As a result, Kim (1997) indicates that in South Korea, total spending (public and private) on education was $13.3 \%$ of the GDP in 1984, compared to 5.7\% in Japan in 1982 and $6.7 \%$ in the United States in 1981. Interestingly, the majority of private spending on education was dedicated to sending students to unofficial institutions in order to complement their formal studies.

The clan, understood as the family or the work group, plays an important role in social and economic relationships. For example, it is common for Korean firms to be operated by members of the owner's immediate family, other relatives or people from the area, so as to manage the business almost as if it were a family unit. It is also common for Korean firms to engage in economic transactions with members of the clan. In this sense, the clan helps to generate cohesion and a system of reciprocal obligations that provide mechanisms for conflict management.

South Korean society emphasizes harmonious interpersonal relationships. Confucian-influenced cultures conceive of the community as a means to their betterment as human beings. This process emerges as a result of the individual's interactions with the rest of the community. These cultures think of the community first as the family, then the neighborhood, the nation, the world and, finally, the universe (understood in religious terms). Cooperation, consensus and social solidarity between members of an organization are important in the organization's decision making processes, which creates a distinctive organizational dynamic in Korean firms. It is worth mentioning that collectivism is not as strong in South Korea as it is in Japan; however, it shows a sharp contrast with the individualism and competitiveness of the West (Chang, 1983).

Last, discipline is a basic element of the social ethos, since it is imposed in the family, school and work. Under the assumption that one's conduct is all-determining, Confucianism demands that changing one's environment requires first changing one's conduct. For human beings, moral qualities do not develop by themselves; on the contrary, they are cultivated in a process of self-education and self-knowledge.

\section{The Manifestation of Values of Confucian Origen in South Korean Society}

Neither Confucianism nor neo-Confucianism alone can explain the marked dynamism in South Korean society. Thus, we must consider the contingent and situational elements that surround the economic and technological develop of South Korea. Along these lines, we could consider the level of individual compromise among South Koreans to stem from their entrepreneurial attitude, organizational discipline and the possibility of social mobility along with the establishment of a job network. 
Vogel (1991) points out that, on an individual level, South Koreans can resist long days of monotonous work. The underlying question, then, is what makes South Koreans such assiduous workers. According to Kim (1997), there are six positioning factors: first, tenacity; second, the han psyche; third, conditioning during the education process in schools; fourth, physical environment; fifth, the spirit of "beating" Japan; and sixth, the experience of privation.

The tenacity to undergo hardship is a profoundly rooted Korean characteristic. As a small nation surrounded by large ones (China, Mongolia, Russia, Japan), Korea has a history of frequent invasion, which led it to be often governed by invaders during long periods of time. Regardless, Koreans refused to succumb to these invaders, and thus endured suffering and confusion and adapted to the privation imposed on them for thousands of years. Even so, Koreans still uniquely maintain their language and culture. As a result, the tenacity to endure privation has led Koreans to develop the second factor, called the han psyche.

The Korean word han means resentment, which are common in the Korean way of thinking. This aspect of the Korean mentality developed as a result of permanent frustration, repressed anger, evasions, remorse and the inability to change the situations of their families and societies during the frequent foreign occupations. Culturally, parents require their children to be responsible and dutiful; employers require their employees to be compromised and disposed; governors, national and foreign, require the governed to be obedient. As such, children, employees and members of a society in general must not only repress their feeling of rage and frustration towards their parents, superiors or leaders, but they must also maintain an attitude of respect and refrain from reacting to provocation. On the other hand, as codependent on and coexisting with the Western way of life, a South Korean with a han mentality have a strong need to shine in all aspects of life, in order to gain the approval of their superiors: "That han is a source of energy that drives Koreans to work with a kind of frenzy, to be tenacious to sacrifice themselves for the betterment of their families and country" (Kim, 1997, p. 70).

The majority of South Koreans are also accustomed to arduous work from their days at school. Like their counterparts in Eastern Asian countries such as Japan, Singapore, Taiwan and Hong Kong, the majority of South Korean students undergo grueling exams. Students often spend numerous hours per day in extracurricular educational programs, in order to develop a solid foundation for their future years of assessment. Acquiring the discipline to study ten to twelve hours a day is not unusual for South Korean students. South Koreans, like their neighbors, are accustomed to long days of frenetic work.

Korea's physical landscape also compelled the creation of an environment of hard work. The scarcity of raw materials, "tight" territorial conditions and a crude winter, along with the national spirit of competition, appear to have forced Koreans to work arduously in order to survive an unfavorable environment: "Korea is crossed by mountains with only one-third of the land inhabitable or arable and that yields only one crop a year owing to severe winter weather" (Kim, 1997, p. 71).

Also, while South Koreans admire and try to emulate the economic success of Japan, the older generations remember clearly the brutal Japanese occupation. The desire to "beat" Japan has been an energizing force for all Koreans. Through indoctrination in schools, this spirit has taken root in the new generation. Last, given their memories of deprivation during the Japanese occupation and the Korean War, Koreans are grateful to find work, and it is common for South Koreans to work an average of ten to twelve hours a day. Administrators work much more, averaging between seventy and eighty hours a week. However, this pace of work appears to come at a devastating price. According to Kim (1997), the South Korean newspaper Joong Al Ilbo reported that, in 1989, the mortality rate attributable to stress in South Korean men between forty and fifty was 2.3 times higher than that of their counterparts in other Eastern Asian countries and 3.5 times higher than that of South Korean females. In 1989, the overall mortality rate of the South Korean population was 1.3, compared with fluctuations between 0.3 and 0.5 in countries in other parts of the world.

We must also consider the South Korean entrepreneurial spirit. The government played an important part in the creation and development of the chaebols (Note 1). The government selected innovative family businesses and guided and diversified their market participation, which helped to foster innovation. Vogel (1991) contends of the chaebols: "These entrepreneurs were bolder in exploring risky business than their counterparts in most other countries because the government stood behind them, ready to help" (pp. 61-62). We can also see this entrepreneurial spirit in small firms, which received much less help from the government. For example, the number of firms producing electronics increased from 231 in 1971 to 1026 in 1983, with small firms representing 74\% of the total. Kim $(1980,1997)$ reports that the majority of these firms' founders left their businesses in order to explore new opportunities in the growing industrial sector.

The tendency towards hard work and the entrepreneurial spirit, together with self-knowledge - characteristics of both Confucianism and the Protestant ethic-, reinforced this goal-driven attitude. Almost immediate success in the international market gave South Koreans confidence in their abilities and drove their determination to continue their efforts and reinforced the "can do" spirit when faced with a series of economic and administrative crises. 
This spirit was, for example, well demonstrated in two crises. With Korea relying 100 percent on foreign oil, the manufacturing sector was extremely vulnerable to the fluctuation of the available quantity and its price. When the crisis hit, Korea entered the Middle Eastern countries to exploit the rapidly rising construction service market to earn enough foreign currency to pay for increasing oil prices and to secure oil from the region. Thus Koreans turned the crises into opportunities, which is the coherent story in the process of Korea's industrialization. (Kim, 1997, p. 75)

Another of the situational factors that Kim (1997) indicates is discipline at an organizational level. The relative importance of the group over the individual and the Confucian values that favor collective action are changing. The importance of belonging to a group such as the family or the local community has been diminishing. However, new solidarities have emerged at work places and in lines of work, which has reduced the space for individuals in organizations to behave idiosyncratically: "Group leaders not only teach these values to members but also accept responsibility for members who abide by the values and apply social pressure on those who do not" (Vogel, 1991, p. 98).

\section{Historical Factors}

Although we have demonstrated congruence between the predominant South Korean cultural values and the country's rapid development, this congruence is not sufficient to explain South Korea's success in a determined historical moment. In order to be able to understand the expression of Confucian values in the concrete dynamic in South Korea, we must also analyze the historical circumstances of the time. This analysis demonstrates the considerable weight of historical factors in the understanding of South Korean development.

The North American occupation from 1950 to 1953 helped South Koreans to organize their militia and afforded them military technology and a way to administer it. By 1961, when South Korean military leaders took power, the military organization style filtered into the government bureaucracy and became the dominant organizational system. We must consider that the South Korean military elite already possessed firm notions of organization and discipline, as they had been educated in Japan during the years of the Japanese occupation of Korea.

Military culture and discipline has a direct influence on life in South Korea because of a military service requirement of between two and three years. During this service, young South Koreans receive military training and the strictest discipline, providing them with the experience of organizational life. South Koreans fulfilling their military service requirement and enlisted men and women learn to manage work groups of various sizes, while officials are in charge of administering military technology. It is unsurprising for retired military officers to enter private firms as administrators. This development has become the basis of growth for the chaebols (Kim, 1997).

The Korean War radically transformed Korean society. The massive exodus of North Korean communists to South Korea and the social confusion during the war caused the amalgamation not only of the people of the different regions of Korea, but also of different families and social status. This made Korean society significantly more flexible and mobile that it had been before the war. It is also possible that the obligatory military service united youth from different geographical regions and social origin, which weakened social barriers. This dynamic of flexibility and social mobility favored industrial development, which led to rapid urbanization. Industrial development allowed for high labor mobility. However, South Koreans, in contrast with their Japanese counterparts, enjoyed the individual liberty and opportunities that South Korean's industrial expansion offered them. As a result, the average rate of mobility in South Korean firms in 1979 was $5 \%$, higher than in the United States (4\%) or Japan (2\%). This high labor mobility resulted in a rapid diffusion of technology among firms.

As the last in this series of historical factors, we stress the nationalism that the Japanese occupation incited. Geographically speaking, the historical Korean territory is small (one can cross it in half a day) with nearly unvarying natural conditions, which has allowed Koreans historically to maintain a practically uniform lifestyle. We can see this reflected in racial and linguistic homogeneity, which favor cultural homogeneity: "Uniformity in education in terms of textbooks, school rituals, and centralized administration has been the major tool in shaping the national uniformity that bred a nationalistic character among the people" (Kim, 1997, p. 75).

The frequent invasions and the 36-year Japanese occupation forged in Koreans a sense of nationalism so strong that, when it comes to athletic competition, South Korea and North Korea have forgotten their differences with the sole goal of beating Japan. This nationalism is also manifest in employment. According to L. Kim (1997), not even one foreign company has made the list of the best employers in South Korea. Furthermore, among the Korean students who study in American universities, $67.5 \%$ plan to return to Korea and work in a national firm, while only $15.7 \%$ wish to work in a foreign company.

\section{Conclusion}

After analyzing the role of South Korea's Confucian cultural heritage, we can conclude that this tradition's values remain present in government and social life, if we allow a margin for interpretation of these values in a contemporary 
context. The structure of the South Korean public administration presents features such as a hierarchical unity of the State apparatus, a meritocratic conscription of public servants and a sense of responsibility towards the people. These characteristics of the South Korean government are important factors in the society's development, at least in principle. Furthermore, we can demonstrate the congruence of cultural values such as discipline and education with Confucian heritage; these are also elements of the social structure that has propelled South Korean development.

However, the congruence between Confucianism, public administration and social values is not a sufficient condition to explain South Korea's development. If we were to contend that the Confucian cultural matrix were a sufficient factor to explain South Korea and other Eastern Asian countries' economic success, we would have to explain why this development did not occur in other historical times. As such, we must also consider the historical-situational factors that led South Korean society to such a rapid advance in development. In particular, South Korea's relationship with Japan and the United States served as a source for the creation of a unique developmental model, the strengthening of nationalism and the acquisition of material and intellectual resources.

Evidently, a set of values establish conditions favorable to a certain social dynamic, and in this sense Confucianism has been undoubtedly a positive factor for structuring the government and society, which have let South Korea to the level of development that it currently enjoys. However, economic and technological development has occurred in other social contexts and distinct historical conditions. This leads us to the conclusion that economic-technological development is possible is distinct cultural contexts and is not bound to a set of specific cultural conditions. Furthermore, the existence of a set of favorable values is not sufficient to generate a dynamic of development in a specific society; these values must be embodied in a political, social and economic structure that has the capacity to favor the goals that a society establishes for itself.

\section{References}

Amsden, A. (1989). Asia's next giant: South Korea and late industrialization. New York: Oxford University Press.

Chang, C. S. (1983). Comparative Analysis of Management Systems: Korea, Japan, and the United States. Korea Management Review, 13(1), 77-89.

Chau, D. M. (1996). Administrative concepts in Confucianism and their Influence on development in Confucian countries. Asian Journal of Public Administration, 18(1), 45-69.

Creel, H. (1964). The beginning of bureaucracy in China: The origin of Hsien. Journal of Asian Studies, 23(2), $155-184$.

Friedman, M., \& Friedman, R. (1980). Free to choose: A personal statement. New York: Harcourt Brace Jovanovich.

Hague, R., Harrop, M., \& Breslin, S. (1992). Comparative government and politics. Hong Kong: Macmillan.

Harris, N. (1986). The end of the Third World: Industrialising countries and the decline of an ideology. London: Penguin Books.

Hsu, L. (1975). The political philosophy of Confucianism. London: Curzon Press.

Hughes, H. (1993). Development policy and development performance. Perth, Australia: University of Western Australia.

Johnson, C. (1995). Japan: who governs? The rise of the developmental state. New York: Norton.

Kahn, H. (1979). World economic development: 1979 and beyond. London: Croom Helm.

Katz, J. (2000). The dynamics of technological learning during the import-substitution period and recent structural changes in the industrial sector of Argentina, Brazil and Mexico. In L. Kim, \& R. Nelson. Technological learning and innovation. New York: Cambridge University Press. 307-334.

Kim, L. (1980). Stages of development of industrial technology in a developing country: A model. Research Policy, 9, 254-277.

Kim, L. (1997). Imitation to innovation: The dynamics of Korea's technological learning. Cambridge, MA: Harvard University Press.

Lee, D. Y. (1985). An outline of Confucianism. Bloomington: Eastern Press.

Lee, K. (1993). New East Asian economic development: Interacting capitalism and socialism. New York: Sharpe.

Lodge, G. C., \& Vogel, E. F. (1987). Ideology and national competitiveness. Boston: Harvard Business School.

Moulder, F. V. (1977). Japan, China and the modern world economy. Cambridge: Cambridge University Press.

Park, C. H. (1970). Our nation's path: Ideology of social reconstruction. Seoul: Hollym Corp.

Porter, M. (1980). Competitive Strategy. New York: Free Press.

Schwarzmantel, J. (1987). Structures of power: An introduction to politics. New York: St. Martin Press. 
Steers, R., Shin, Y. K. \& Ungson, G. (1989). The Chaebol: Korea's new industrial might. New York: Harper \& Row.

Vogel, E. F. (1991). The four little dragons: The spread of industrialization in East Asia. Cambridge, MA: Harvard University Press.

Wade, R. (1990). Governing the market: Economic theory and the role of government in East Asian industrialization. Princeton, NJ: Princeton University Press.

Weber, M. (1989). La ética protestante y el espíritu del capitalismo. Mexico City: Miguel Angel Porrúa.

Wei-ming, T. (1984). Confucian Ethics Today: The Singapore Challenge. Singapore: Federal Publications.

World Bank. (1993). The East Asian miracle. Washington D.C.: Oxford.

Notes

Note 1. According to Steers, Shin and Ungson (1989), a chaebol "is a business group consisting of varied corporate enterprises engaged in diversified business areas and typically owned and managed by one or two interrelated family groups." (27)

\section{Tables}

Table 1. Indicators of Human Development in Korea

\begin{tabular}{|c|c|c|c|c|c|c|}
\hline & 1953 & 1960 & 1970 & 1980 & 1990 & 1994 \\
\hline Illiteracy Rate (\%) & 78.0 & 27.9 & 10.6 & NA & NA & NA \\
\hline $\begin{array}{l}\text { Elementary School (\%) (ages } \\
6-11)\end{array}$ & 59.6 & 86.2 & 102.8 & 101 & 100.7 & 100.5 \\
\hline Middle School (\%) (ages 12-14) & 21.1 & 33.3 & 53.3 & 94.6 & 98.7 & 99.0 \\
\hline High School (\%) (ages 15-17) & 12.4 & 19.9 & 29.3 & 68.5 & 86.9 & 88.7 \\
\hline Tertiary School (\%) & 3.1 & 5.0 & 8.7 & 16.0 & 37.7 & 48.8 \\
\hline $\begin{array}{l}\text { Graduates of Vocational } \\
\text { Training Centers }(1,000)\end{array}$ & NA & NA & 28.2 & 104.5 & 67.7 & 184.4 \\
\hline $\begin{array}{l}\text { Number of Junior College } \\
\text { Graduates }(1,000)\end{array}$ & NA & NA & 7.8 & 51.5 & 87.1 & 128.4 \\
\hline $\begin{array}{l}\text { Number of University Graduates } \\
(1,000)\end{array}$ & NA & 18 & 28.2 & 52.2 & 170.9 & 183.4 \\
\hline $\begin{array}{l}\text { Number of Graduates from } \\
\text { Tertiary Schools (per 10,000 } \\
\text { population) }\end{array}$ & NA & $6.6^{*}$ & 11.4 & 27.7 & 59.4 & 69.5 \\
\hline
\end{tabular}

The above table provides data on illiteracy rates, rates of enrollment as a percentage of the corresponding age group, and numbers of graduates of vocational and tertiary education programs. Source: Kim, 1997, p. 61.

*Data from 1963. 